\title{
Calculation and Selection of Flat-Plate Solar Collector Geometric Parameters with Thermosiphon Circulation
}

\author{
Yedilkhan Amirgaliyev ${ }^{1,4}$, Murat Kunelbayev' ${ }^{1}$ Waldemar Wójcik²*, \\ Beibut Amirgaliyev ${ }^{3}$, Aliya Kalizhanova ${ }^{1,4}$, Omirlan Auelbekov', \\ Nazbek Kataev ${ }^{1}$, Ainur Kozbakova ${ }^{1,5}$ \\ 1 Institute Information and Computational Technologies CS MES RK, Pushkin St 125, Almaty, Kazakhstan \\ 2 Lublin University of Technology, ul. Nadbystrzycka 38A, 20-618 Lublin, Poland \\ 3 International University of Information Technologies, Kazakhstan \\ ${ }^{4}$ Al-Farabi Kazakh National University, 71 al-Farabi Ave., 050040, Almaty, Kazakhstan \\ 5 Almaty University of Power Engineering and Telecommunications, Baytursynov Street 126, 050013 Almaty, \\ Kazakhstan \\ * Corresponding author's e-mail: waldemar.wojcik@pollub.pl
}

\begin{abstract}
The article describes a newly developed calculation technique and the choice of the geometrical parameters of the solar collector with the siphon effect. The dependence of the cross section of the pipe on the flow time for different values of the head is also shown. With an increase in the siphon head, the flow time of the liquid increases as well. This is explained by the fact that with increasing head, the hydraulic resistance of the siphon rises, which leads to a decrease in the velocity of the fluid. For the first time, a relationship determining the time of fluid outflow in dependence on the geometric parameters of the solar collector is formulated. The developed technique allowed to establish that the local hydraulic resistance and friction play a significant role in the heat carrier flow rate.
\end{abstract}

Keywords: solar energy, flat solar collector, thermal siphon circulation, geometric parameters

\section{INTRODUCTION}

Production of hot water is one of the most relevant aspects in the solar energy industry, and the demand for hot water is being noticeably increased, especially in the residential sector. The components of the solar system include solar collectors and reservoirs for the heat storage. The tank for the storage plays a significant role in the solar energy system, when it is available and delivers the heat upon the necessity. The work of the heating solar systems is strongly dependent on the thermal stratification. Since the 1970s, the stratification of the reservoir was intensively studied [Lavan 1977, Wood 1981, Haller 2009]. Low flow was thermally stratified and showed that the reservoirs-storages supply $17 \%$ more of solar energy to the load [Sharp 1979, Wuestling 1985, Fanney 1988, Hollands 1989, Kleinbach
1993]. The authors have noted that the advantage of the thermal stratification is in water heating by the solar system. Christophari et al. [Cristofari 2003] discovered that along with a high degree of stratification, the energy conservation is higher (5.25\% of the total use), comparing to a completely mixed reservoir. However, the hotter reservoir, the thermal stratification degree of which is defined by temperature as the temperatures difference between the upper and lower reservoir parts, is designed for meeting the demand on the energy and is extremely important for an efficient operation of the energy systems solar panels. Many parameters have an impact on the thermal storage performance, including reservoir geometry, [Eamesi 1998, Nelson 1999, Hobbi 2009, Lundh 2010], reservoir volume and collector area [Shariah 1995, Bojic 2002, Rodríguez 2012, Kim 2012]; therefore, a lot of solutions were offered 
and a number of models was developed. Amongst them, the most popular one is the one-dimensional model [Kleinbach 1993, Papanicolaou 2009], securing the appropriate assessment of temperature distribution in the tank. Upon working with the thermal stratification, an initial and important element influencing the system productivity is the mass flow rate from the hot source (solar collectors) and/or load. For the point-to-point systems (SDHW - Solar Domestic Hot Water) it is known that the rate of mass flow, entering the storage reservoir represents the same flow release from the collector [Kurz 2012, Zajkowski 2015].

In sharing, several collectors, which are fixed to receive the optimized capture within a year are used. Solar collectors can be connected together sequentially or in parallel. In spite of the fact that parallel connection is preferable to several users, some problems, such as loss of heat and pressure drop, appear. Sequential and parallel series connections are used in many countries in case the system has been optimized and it is necessary to account for the impact of liquid distribution [Quijera 2011, Armenta 2011]. While collecting tanks are installed sequentially it is assumed that the mass flow rate is similar in every collector and the water temperature at output is being increased from one collector to another. It leads to the heat loss increase due to the growing difference between the collector's input and output temperatures. Luminosu and Fara [Luminosu 2005], Atkins et al. [Atkins 2010] showed that the energy efficiency is continuously decreasing upon increasing the collecting surface through serial connection of flat-plate solar collectors. For parallel connections between collectors or massive collectors, the total mass flow rate being returned from the reservoir storage is broken down into several flows, and the water output temperature is analogous when the collectors are identical.

Garg [Garg 1973] demonstrated in his research that the true parallel location of moisture absorbers tanks gives maximum performance and economy. Morrison [Morrison 2001] noted that using the collectors sequentially, in parallel or sequentially-parallel on the ground of hydraulic designing of minimum pressure drop has equal division between all collectors in the massif. Kalogirou [Kalogirou 2009] noted that the field should be constructed from identical modules of sequential or parallel or sequentially-parallel collectors. He also observed that the modules should be switched on in reverse to secure the self-balanced massif, as all collectors operate with similar pressure fall.
Dubey and Tivari [Dubey 2009] have studied the analysis of PV / T flat plates collectors connected sequentially. They demonstrated that the amount of series collectors influences the mass flows.

Thermal siphons are widely used in the domestic sector and different studies on their thermal characteristics have been described [Shitzer 1978, Mishra 1992, Shariah 1996] as well as in [Karaghouli 2001, Belessiotis 2002]. Thus, the solar energy adds liquid power into the collector's absorber. The density difference is created by the temperature difference and the water natural circulation exists (thermal siphon effect), upon which the thermal water ascends and cold water flows descend. The thermal behavior of systems is connected with multiple interconnected parameters, such as solar radial and weather conditions, water flow through collector, reservoir configuration (vertical or horizontal), heat-exchange unit efficiency (for indirect heating system) and thermal capacity. At night, heat loss (or thermal siphon reverse flow) represents an additional serious problem [Michaelides 2011].

Apart from that in order to increase the coefficient of thermal efficiency, it is very important to stimulate and keep temperature stratification in the tank. Upon collectors low flows the thermal siphon reservoir might have the high temperature of stratification, as cold flow is mixed with the lower stratum only. However, higher mass flow rate due to hot water diversion from the tank can cause serious problems of stratification temperature and completely mixed reservoir might cause serious heat losse s[Young 1981, Young 1984].

\section{METHOD}

In our work we developed calculation methods and selection of siphon effect solar collector's geometric parameters. The siphon effect solar collector effective operation is influenced by a number of factors, such as solar radiation intensity, environment temperature, solar siphon collectors geometrical parameters, absorber and heat conductor thermal-physical parameters, elements materials, as well as other factors, having impact at the final temperatures and the system's operation mode. The liquid flow time $\tau=f\left(d, H, G_{0}\right)$, pipeline geometrical parameters $B=f(d, d, R)$, liquid's temperatures in the solar collector $t=f(F, I, V, \rho, m)$ and liquid's temperature in the tank - accumulator $t_{\sigma a}=f(d, h, V)$. 
In order to ensure that the siphon effect of solar collector operates with maximum efficiency, it is necessary to provide certain balance of the siphon's geometrical parameters, dosing tank with a collector's geometrical parameters, as well as to set the rational flow of heat conductor from the solar collector.

Let us define the siphon geometrical parameters during filling and release of the liquid through a siphon. In order to solve the task, let us consider a design model, given in Figure 1.

Initial design data of the accepted model:

$\mathrm{H}$ - discharge head $\mathrm{m}$;

$\mathrm{h}$ - pipeline length to the elbow (siphon height), $\mathrm{m}$;

$\mathrm{d}$ - siphon diameter, $\mathrm{m}$;

$\mathrm{F}_{\text {base }}-$ dosing tank's base area, $\mathrm{m}^{2}$;

$v$ - liquid speed, $\mathrm{m} / \mathrm{s}$;

$V$ - dosing tank volume, $\mathrm{m}^{3}$;

$G$ - liquid flow in the dosing tank, $\mathrm{m}^{3} / \mathrm{s}$.

Liquid volume in a dosing tank might be calculated as:

$$
V=F \cdot H
$$

where: $F$-dosing tank's base area, $\mathrm{m}^{2}$, $\mathrm{H}$ - fluid head, $\mathrm{m}$.

Herewith the tank filling time $\tau_{1}$ is defined as follows:

$$
\tau_{1}=\frac{V}{G}
$$

where: $V$ - liquid volume in the dosing tank, $\mathrm{m}^{3}$;

$G$ - liquid flow rate, $\mathrm{m}^{3} / \mathrm{s}$.

Let us define heat conductor flow time through a siphon, which is in general the water

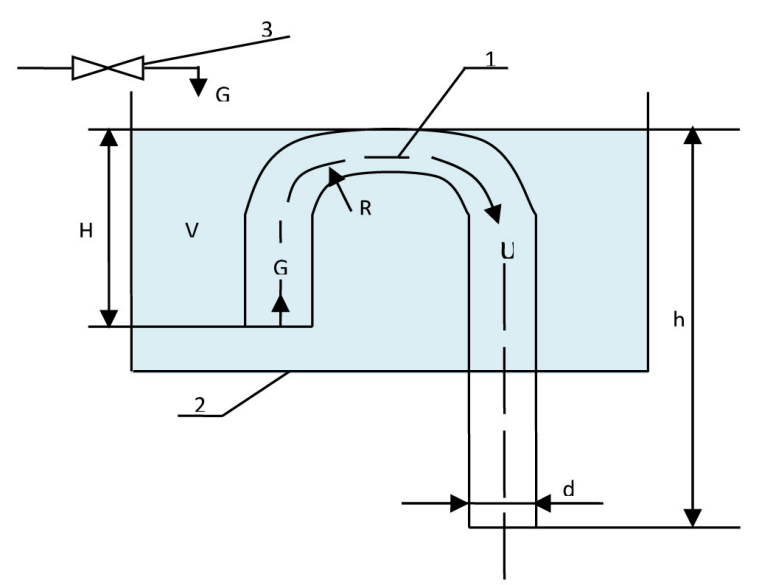

Figure 1. Designed physical model of a dosing tank with a siphon: 1 - dosing tank's siphon; 2 - dosing tank; 3 - pipeline with a valve for cold water. head function $\mathrm{H}$, pipeline diameter $\mathrm{d}$ and the flow through a siphon $\mathrm{G}$

$$
\tau_{2}=f\left(d, H, G_{0}\right)
$$

The liquid flow time through a siphon might be determined as follows

$$
\tau=\frac{V}{G_{0}}
$$

where: $G_{0}$ - liquid flow through a siphon, $\boldsymbol{M}^{3} / c$.

In its turn, the flow can be presented as:

$$
G_{0}=\vartheta \cdot f
$$

where: $\vartheta$ - liquid speed, $\mathrm{m} / \mathrm{s}$;

$f$-cross sectional area, $\mathrm{m}^{2}$.

Let us calculate a siphon's cross sectional area $f$ as:

$$
f=\frac{\pi \cdot d^{2}}{4}
$$

where: $d$-pipe diameter, $\mathrm{m}$.

The value of the liquid flow speed $\vartheta$ is defined from the condition of water free flow from the vessel. Thereupon:

$$
\vartheta=\sqrt{2 g \cdot H}
$$

where: $g$-gravitational acceleration, $\mathrm{m} / \mathrm{s}^{2}$; $H$ - water head, $\mathrm{m}$.

With account of (6), (5) and (4) the expression (3) is as follows:

$$
\tau_{2}=\frac{F \cdot H}{\sqrt{2 g \cdot H} \pi d^{2} / 4}
$$

As it is known, upon liquid flow through a siphon, a water head loss $\mathrm{H}_{\text {loss }}$ takes place, formed from losses due to the friction $h_{m p}$ in the pipeline and losses due to local resistance $h_{k}$ (losses in an elbow):

$$
H_{\text {nom }}=h_{m p}+h_{k}
$$

where: $h_{m p}$ - losses along the pipeline length;

$h_{k}-$ losses in an elbow.

Water head losses due to circular pipes friction are defined according to the known formula of Darcy -Weisbach /1/:

$$
h_{m p}=\lambda \frac{\ell}{d} \frac{\vartheta^{2}}{2 g}
$$


where: $\ell$ - pipeline length, in our case it correspondingly equals $\ell=H+h$;

$\lambda$ - pipe friction factor upon turbulent liquid flow;

$\lambda=0,11 \cdot\left(\frac{K_{y}}{d}+\frac{68}{R_{i}}\right) \cdot 0,25$

where: $R_{0}=\frac{\vartheta \cdot d}{v}-$ Reynolds number for circular pipes;

$v=1 \cdot 10^{-6} \mathrm{~m}^{3} / \mathrm{s}-$ liquid kinematical viscosity.

Water head loss in an elbow happens due to the liquid flow direction change and it is defined as follows:

$$
h_{k}=\xi \cdot \frac{\vartheta^{2}}{2 g}
$$

where: $\xi$ - local resistance non-dimensional factor. Upon rotation of pipelines for $90^{\circ}$ it is defined according to Altshuller formula $/ 2 /$ :

$$
\xi_{90^{0}}=\left[0,2+0,001(100 \cdot \lambda)^{8}\right] \cdot \sqrt{d / R}
$$

where: $R=\frac{d}{4}-$ hydraulic radius for circular pipes.

Upon any angle, quarter-turn it takes the form of

$$
\xi=\xi_{90^{0}} \cdot a
$$

where $a-\mathrm{a}$ factor, depending on the turning angle,

$a=1.33 / 104,105 /$

At liquid flow through a siphon the liquid movement is unsteady. In such case, the water head $\mathrm{H}$ changes with the course of time; consequently, the flow $G$ changes as well. Let us consider the flow process: at some instant the liquid level is at $h$ height During infinitesimal little period of time $d \tau$, the level changes for a small value $d h$. During $d \tau$ the liquid movement might be considered as stable. Then, for the time $d \tau$ the following liquid volume flows out of the siphon:

$$
d V=G d \tau \text { or } d V=d \sqrt{2 g h d \tau}
$$

out of the other side:

$$
d V=F d h
$$

Setting equal the right-hand sides of equation, we obtain:

$$
\begin{gathered}
F d h=d \sqrt{2 g h d \tau} \\
d \tau=\frac{F d h}{d \sqrt{2 g h}}
\end{gathered}
$$

The time of liquid flow from the level $\mathrm{H}_{1}$ to the level $\mathrm{H}_{2}$ is an integral from $h=H_{1}$ to $h=H_{2}$

$$
\begin{gathered}
\tau=\int_{I_{1}}^{I_{2}} \frac{F d h}{d \sqrt{2 g h}} \\
\tau=\frac{2 F}{d \sqrt{2 g\left(I_{1}-I_{2}\right)}} \cdot\left(I_{1}-I_{2}\right)
\end{gathered}
$$

The point of time, when the liquid level reaches the lower edge of a siphon's suction part $\dot{I}_{2}=0$, the time of complete flow is calculated according to the formula:

$$
\tau=\frac{2 F I}{d \sqrt{2 g I_{1}}}
$$

The obtained dependences allow tracing the interrelation of flow time through a siphon in relation to $\mathrm{H}$ siphon water head value and its geometrical parameter (channel cross-section area). Figure 2 presents those dependences diagrams, where it is shown that the larger the cross-section of the siphon tube, the more intensive the drop in the expiration time. It can

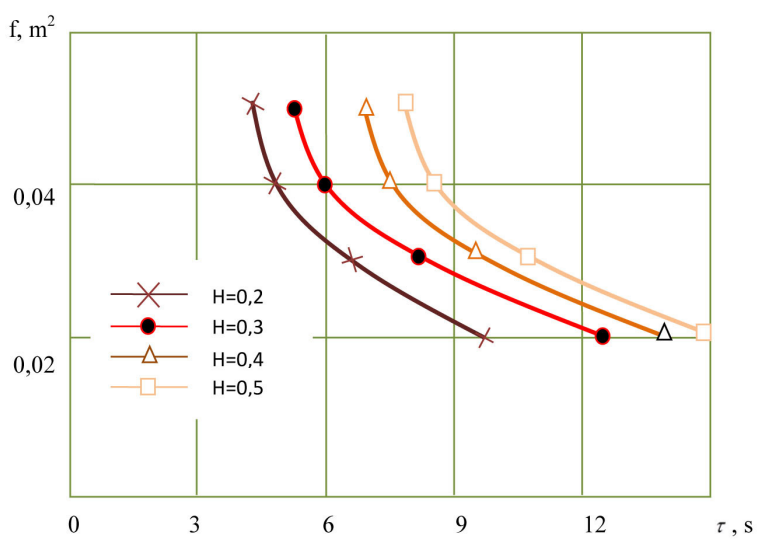

Figure 2. Dependence of channel cross-section area on the liquid flow time at different water head values 
also be seen that with an increasing siphon pressure, the expiration time is increased as well. This can be explained by the fact that when the pressure increases, the hydraulic resistance (on friction and local resistance) of the siphon grows, which leads to a decrease in the velocity of the fluid.

\section{CONCLUSION}

The studies confirm the viability of the proposed installation of solar hot water supply using a collector with a siphon effect. For the first time, a relationship determining the time of fluid outflow in dependence on the geometric parameters of the solar collector is established. In general, as we observe from our calculations, the developed technique enabled to establish that local hydraulic resistance and friction have a significant effect on the coolant flow rate.

\section{Acknowledgements}

This work is supported by grant from the Ministry of Education and Science of the Republic of Kazakhstan within the framework of the Project BR05236693 "Mathematical and computer models, hardware and software tools and experimental development on creation of network combined effective dual-circuit solar collectors with thermosiphon circulation and monitoring of their functioning".

\section{REFERENCES}

1. Armenta C., Vorobieff P., Mammoli A. 2011. Summer off peak performance enhancement for rows of fixed solar thermal collectors using flat reflective surfaces. Solar Energy 85(9), 2041-2052.

2. Atkins M.J., Walmsley M.R.W., Morrison A.S. 2010. Integration of solar thermal for improved energy efficiency in low-temperature-pinch. Industrial Processes Energy 35(5), 1867-1873.

3. Belessiotis V., Mathioulakis E. 2002. Analytical approach of thermosyphon solar domestic hot water system performance. Sol. Energy, 72, 307-315.

4. Bojic M., Kalogirou S., Petronijevic K. 2002. Simulation of a solar domestic water heating system using a time marching model. Renewable Energy 27(3), 441-452.

5. Cristofari C., Notton G., Poggi P., Louche A. 2003. Influence of the flow rate and the tank stratification degree on the performances of a solar flat-plate collector. International Journal of Thermal Sciences 42(5), 455-469.

6. Dubey S., Tiwari T. 2009. Analysis of PV/T flat plate water collectors connected in series. Solar Energy, 83(9), 1485-1498.

7. Eamesi P.C., Norton B. 1998. The effect of tank geometry on thermally stratified sensible heat storage subject to low reynolds number flows. International Journal of Heat and Mass Transfer 41(14), 2131-2142.

8. Fanney A.H., Klein S.A. 1988. Thermal performance comparisons for solar hot water systems subjected to various collector and heat exchanger flow rates. Solar Energy 40 (1), 1-11.

9. Garg H.P. 1973. Design and performance of a largesize solar water heater. Solar Energy 14, 303-312.

10. Haller M.Y., Cruickshank C.A., Streicher W., Harrison S.J., Andersen E., Furbo S. 2009. Methods to determine stratification efficiency of thermal energy storage processes-review and theoretical comparison. Solar Energy, 83(10), 1847-1860.

11. Hobbi A., Siddiqui K. 2009. Optimal design of a forced circulation solar water heating system for a residential unit in cold climate using TRNSYS. Solar Energy 83(5), 700-714.

12. Hollands K.G.T., Lightstone M.F. 1989. A review of low-flow stratified-tank solar water heating systems. Solar Energy 43(2), 97-105.

13. Kalogirou S.A. 2009. Solar energy engineering: processes and systems. Elsevier, London.

14. Karaghouli A.A., Alnaser W.E. 2001. Experimental study on thermosyphon solar water heater in Bahrain. Renew. Energy, 24, 389-396.

15. Kim Y.D., Thu K., Bhatia H.K., Charanjit Singh Bhatia C.S., Kim Choon Ng. 2012. Thermal analysis and performance optimization of a solar hot water plant with economic evaluation. Solar Energy 86(5), 1378-1395.

16. Kleinbach E.M., Beckman W.A., Klein S.A. 1993. Performance study of one-dimensional models for stratified thermal storage tanks. Solar Energy 50(2), 155-166.

17. Kurz D. 2012. Comparative analysis of photovoltaic panel and solar roof tile in application to family housing. IAPGOS 2 (4b), 17-20

18. Lavan Z., Thompson J. 1977. Experimental study of thermally stratified hot water storage tanks. Solar Energy, 19(5), 519-524.

19. Luminosu I., Fara L. 2005. Determination of the optimal operation mode of a flat solar collector by exergetic analysis and numerical simulation. Energy 30(5), 731-747.

20. Lundh M., Zass K., Wilhelms C., Vajen K., Jordan U. 2010. influence of store dimensions and auxil- 
iary volume configuration on the performance of medium-sized solar combisystems. Solar Energy 84(7), 1095-1102.

21. Michaelides I., Eleftheriou P., Siamas G.A., Roditis G., Kyriacou P. 2011. Experimental investigation of the night losses of hot water storage tanks in thermosyphon solar water heaters. J. Renew. Sustain. Energy, 3, 033103:1-033103:9.

22. Mishra R.S. 1992. Theoretical and experimental studies of pressurized and non-pressurized solar water heating systems of thermosyphonic type. Renew. Energy, 2, 371-384.

23. Morrison G.L. 2001. Solar collectors. J. Gordon, Ed., Solar energy-the state of the art-ISES Position Papers, James and James Science Publishers, London, 145-221.

24. Nelson J.E.B., Balakrishnan A.R., Srinivasa-Murthy S. 1999. Experiments on stratified chilledwater tanks. International Journal of Refrigeration 22(3), 216-234.

25. Papanicolaou E., Belessiotis V. 2009. Transient development of flow and temperature fields in an underground thermal storage tank under various charging modes. Solar Energy 83(8), 1161-1176.

26. Quijera J.A., Alriols M.G., Labidi J. 2011. Integration of a solar thermal system in a dairy process. Renewable Energy 36(6), 1843-1853.

27. Rodríguez-Hidalgo M.C. 2012. Domestic hot water consumption vs solar thermal energy storage: the optimum size of the storage tank. Applied Energy 97, 897-906.
28. Shariah A.M., Ecevit A. 1995. Effect of hot water load temperature on the performance of a thermosyphon solar water heater with auxiliary electric heater. Energy Conversion and Management 36(5), 289-296.

29. Shariah A.M., Lof G.O.G. 1996. The optimization of tank-volume-to-collector-area ratio for a thermosyphon solar water heater. Renew. Energy, 7, 289-300.

30. Sharp M.K., Loehrke R.I. 1979. Stratified thermal storage in residential solar energy applications. Energy 3(2), 106-113.

31. Shitzer A., Kalmanoviz Y., Zvirin Y., Grossman G. 1978. Experiments with a flat plate solar water heating system in thermosyphonic flow. Sol. Energy, 22, 27-33.

32. Wood R.J., Al-Muslah S.M., O'Callaghan P.W., Probert S.D. 1981. Thermally stratified hot water storage systems. Applied Energy, 9(3), 231- 242.

33. Wuestling M.D., Klein S.A., Duffie J.A. 1985. Promising control alternatives for solar water heating systems. Journal of Solar Energy Engineering 107(3), 215-221.

34. Young M.F., Bauhn J.W. 1981, An investigation of thermal stratification in horizontal storage tanks. ASME J. Sol. Energy Eng. 103, 286-290.

35. Young M.F., Berguam J.B. 1984. The performance of a thermosyphon solar domestic hot water system with hot water removal. Sol. Energy, 32, 655-658.

36. Zajkowski M., Prorok M. 2015. Propagation analysis of "cold roof" solar systems. Przeglad Elektrotechniczny 91(7), 89-92. 